Tropical Journal of Pharmaceutical Research March 2019; 18 (3): 479-484

ISSN: $1596-5996$ (print); 1596-9827 (electronic)

(C) Pharmacotherapy Group, Faculty of Pharmacy, University of Benin, Benin City, 300001 Nigeria.

\title{
Effect of Yugan Sanjie decoction on expressions of regulatory T cells, serum P21 protein and vascular endothelial growth factor in mice with hepatocellular carcinoma
}

\author{
Song Tan, Aihua Hou, Wei Liu, Jinguo Wang, Xiaoming Huang, Yuejun Mu* \\ Department of Oncology, Yantai Hospital of Traditional Chinese Medicine, 39 Xingfu Street, Zhifu, Yantai, Shandong 264000, \\ China
}

*For correspondence: Email: zr08511@163.com

Sent for review: 8 December 2018

Revised accepted: 28 February 2019

\begin{abstract}
Purpose: To investigate the effect of Yugan Sanjie decoction on the expressions of regulatory $T$ cells (Tregs), serum P21 protein and vascular endothelial growth factor (VEGF) in mice with hepatocellular carcinoma.

Methods: A total of forty specific-pathogen-free (SPF) Kunming mice were randomly assigned to four groups of 10 mice each. Except for normal control group, the other three groups were transfected with hepatoma-22 (H22) cells to establish a mouse model of liver cancer. Mice in the cyclophosphamide group was given cyclophosphamide at a dose of $20 \mathrm{mg} / \mathrm{kg}$ daily intragastrically, while those in decoction group were treated with Yugan Sanjie decoction $(0.4 \mathrm{ml} / \mathrm{kg} /$ day $)$ intraperitoneally. After 30 days of treatment, serum levels of $C D 4^{+} T h 17, C D 4^{+} C D 25^{+}$Treg, Th17/Treg, TNF-a, and VEGF were determined.

Results: There was lower serum level of $C D 4^{+} T h 17$ in the decoction group than in negative control and cyclophosphamide groups $(p<0.05)$. However, higher serum levels of $\mathrm{CD}^{+} \mathrm{CD} 25^{+}$Treg and Th17/Treg were seen in the decoction group, relative to the negative control and cyclophosphamide groups ( $p<$ 0.05). Serum TNF- $\alpha$ was also markedly elevated in decoction group, when compared with negative control and cyclophosphamide groups $(p<0.05)$. Serum VEGF was markedly lower in decoction group than in negative control and cyclophosphamide groups, and was appreciably lower in cyclophosphamide group than in negative control group $(p<0.05)$.

Conclusion: Yugan Sanjie decoction effectively alleviates clinical symptoms of LC, and improves immune function of mice by regulating serum levels of $T$ lymphocytes. These findings provide scientific support for a new treatment strategy.
\end{abstract}

Keywords: Liver cancer, Yugan Sanjie decoction, Regulatory T cells, P21 protein, Vascular endothelial growth factor

This is an Open Access article that uses a funding model which does not charge readers or their institutions for access and distributed under the terms of the Creative Commons Attribution License (http://creativecommons.org/licenses/by/4.0) and the Budapest Open Access Initiative (http://www.budapestopenaccessinitiative.org/read), which permit unrestricted use, distribution, and reproduction in any medium, provided the original work is properly credited.

Tropical Journal of Pharmaceutical Research is indexed by Science Citation Index (SciSearch), Scopus, International Pharmaceutical Abstract, Chemical Abstracts, Embase, Index Copernicus, EBSCO, African Index Medicus, JournalSeek, Journal Citation Reports/Science Edition, Directory of Open Access Journals (DOAJ), African Journal Online, Bioline International, Open-J-Gate and Pharmacy Abstracts

\section{INTRODUCTION}

Liver cancer (LC) is a malignant tumor characterized by slow onset and rapid progression. It is ranked second in the hierarchy of malignant tumors. The early symptoms of LC are generally not obvious until the disease reaches an advance stage. The moment the 
symptoms become obvious, the tumor is already large, and the patient will usually suffer from cachexia and die within a few months. Surgery and conservative treatment are two major strategies for treating $\mathrm{LC}[1,2]$.

In Traditional Chinese Medicine (TCM), LC is described as "liver accumulation, jaundice, abdominal mass, and liver fixity". It is believed that the onset of the disease is related to lack of vitality and dysfunction in the body, and the treatment involves the use of drugs that strengthen the spleen, promote blood circulation, remove phlegm, resolve phlegm and stasis, and soothe the liver [3]. Studies have shown that treatment strategies adopted in TCM for treating LC improve patients' quality of life, prolong survival, and control disease progression.

Yugan Sanjie decoction consists of thirty different types of Chinese herbs. It functions in detoxification, clearing away heat, soothing liver and dampness, and it can be used along with radio- or chemotherapy. It is clinically effective with little or no side effects [4]. The aim of the present study was to investigate the effect of Yugan Sanjie decoction on the expressions of Tregs, serum P21 protein and VEGF in mice with hepatocellular carcinoma.

\section{EXPERIMENTAL}

\section{Experimental mice}

A total of forty specific-pathogen-free (SPF) Kunming mice weighing 15.9 to $22.7 \mathrm{~g}$ (mean weight $=20.5 \pm 1.6 \mathrm{~g}$ ) and aged 3 to 4 weeks, were used in this study. They were housed in metal cages under standard conditions of animal care and provided standard feed and water ad libitum. The mice were randomly assigned to four groups (10 mice per group): normal control group, negative control group, cyclophosphamide group and decoction group.

This research received approval from the Animal Ethical Committee of Department of Oncology, Yantai Hospital of Traditional Chinese Medicine (approval no. 201511936), and was conducted according to the guidelines of "Principles of Laboratory Animal Care" (revised NIH publication 85-23 [5].

\section{Establishment of mouse model of LC}

Except for the normal control group, all groups were transfected with hepatoma-22 ( $\mathrm{H} 22)$ cells to establish mouse model of LC. Cells in exponential growth phase were collected for injection via trypsinization. Cell suspension in a volume of $100 \mu \mathrm{l}$ was adjusted to the required density $\left(1 \times 10^{6}\right.$ cells $)$ for inoculation, and was injected subcutaneously into the hind leg of each mouse, to establish an athymic nude mice with survival of 10 - 12 weeks. The injection sites were monitored until tumors were established. Digital calipers were then used to measure the tumors until they reached sizes of $100-200 \mathrm{~mm}^{3}$.

\section{Preparation of Yugan sanjie decoction}

The decoction consisted of Isatidis Radix (30 g), Astragalus (30 g), Atractylodes macrocephala (15 g), Smilax glabra roxb (15 g), Curcuma aromatica (15 g), Paeonia albiflora pall (10 g), Aurantii fructus (12 g), Polygonati rhizoma (30 g), Bupleurum (10 g), Salvia miltiorrhiza (20 g), Jiaoshanzha $(15 \mathrm{~g})$, and tangerine $(10 \mathrm{~g})$, all of which were dissolved in $1000 \mathrm{ml}$ of distilled water.

\section{Treatment regimen}

The cyclophosphamide group received cyclophosphamide $(20 \quad \mathrm{mg} / \mathrm{kg} \quad$ bwt/day $)$ intragastrically. Mice in decoction group were treated with decoction of Yugan Sanjie $(0.4 \mathrm{ml} / \mathrm{kg}$ bwt/day) intraperitoneally, while the normal and negative control groups did not receive any form of treatment. The treatment lasted for 30 days.

\section{Determination of tumor inhibition}

Tumors removed from the mice were weighed using an electronic balance. The measurements were performed in triplicate, and the mean values were taken. Tumor inhibition $(\mathrm{T})$ was calculated as shown in equation 1 :

$T(\%)=\left\{\left(1-\left(T_{e} / T_{c}\right)\right\} 100\right.$

where $T_{e}=$ tumor weight in experimental group; and $T_{\mathrm{C}}=$ tumor weight in normal control group.

\section{Weight and number of spontaneous activities}

After removal of tumors from the mice, they were weighed every morning using an electronic balance. A stopwatch was used to record the number of spontaneous activities of the mice within 5 min.

\section{Determination of serum levels of Tregs}

Fasting venous blood $(5 \mathrm{~mL})$ was drawn from each mouse in the morning of sacrifice and centrifuged at $3000 \mathrm{rpm}$ for $10 \mathrm{~min}$ to obtain serum which was used for assay of $\mathrm{CD}_{4}{ }^{+} \mathrm{Th} 17$, 
$\mathrm{CD}_{4}{ }^{+} \mathrm{CD}_{25}{ }^{+}$Treg, Th17/Treg using a flow RESULTS

cytometer.

\section{Assessment of immune function}

Serum TNF- $\alpha$ and IL-2 were assayed with appropriate ELISA kits.

\section{Determination of serum levels of P21 protein and VEGF}

Serum P21 protein and VEGF were determined with ELISA kits.

\section{Evaluation of thymus and spleen functions}

Following 30 days of treatment, mice sacrifice was effected via cervical dislocation. The thymus and spleen were removed, washed with ice-cold physiological saline, and weighed using an electronic balance. The thymus $(T)$ and spleen (S) function indices were estimated as shown in Eqs 2 and 3, respectively:

$$
\begin{aligned}
& T=\{w t(m g) / b w t(g)\} \times 10 . \\
& S=\{w s(m g) / b w t(g)\} \times 10
\end{aligned}
$$

where $w t=$ weight of thymus; bwt = body weight; ws $=$ weight of spleen

\section{Statistical analysis}

Data are presented as mean \pm SEM. Statistical analysis was carried out with SPSS version 19.0. Groups were compared using Student's $t$-test and $x^{2}$ test. Statistical significance was fixed at $p$ $<0.05$.

Table 1: Profile of mice in the four groups (n, \%)

\section{Basic profiles of mice}

Number of spontaneous activities, tumor inhibition, survival and mean body weight were markedly higher in the decoction group than in negative control and cyclophosphamide groups $(p<0.05$; Table 1$)$.

\section{Levels of Tregs in the mice}

As shown in Table 2, serum CD4 ${ }^{+}$Th17 level was lower in the decoction group than in negative control and cyclophosphamide groups $(p<0.05)$. However, there were significantly higher serum $\mathrm{CD}_{4}{ }^{+} \mathrm{CD}_{25}{ }^{+}$Treg and Th17/Treg ratio in the decoction group than in the control and cyclophosphamide groups $(p<0.05)$.

\section{TNF- $\alpha$ and IL-2 levels}

As shown in Table 3, serum TNF- $\alpha$ and IL-2 levels were markedly higher in the decoction group than in negative control and cyclophosphamide groups $(p<0.05)$.

Table 3: Levels of TNF- $\alpha$ and IL-2 (ng/L)

\begin{tabular}{lcc}
\hline Group & TNF- $\alpha$ & IL-2 \\
\hline Normal control & $123.23 \pm$ & $105.25 \pm$ \\
& 42.15 & 29.56 \\
Negative control & $132.21 \pm$ & $108.32 \pm$ \\
& 47.23 & 31.25 \\
Cyclophosphamide & $82.15 \pm$ & $75.36 \pm$ \\
& 15.36 & 25.64 \\
Decoction & $299.56 \pm$ & $279.56 \pm$ \\
& $45.23^{* \#}$ & $59.23^{* \#}$ \\
\hline$P<0.05$, relative to negative control group; ${ }^{*} p<0.05$, \\
relative to cyclophosphamide group $(\mathrm{n}=10)$
\end{tabular}

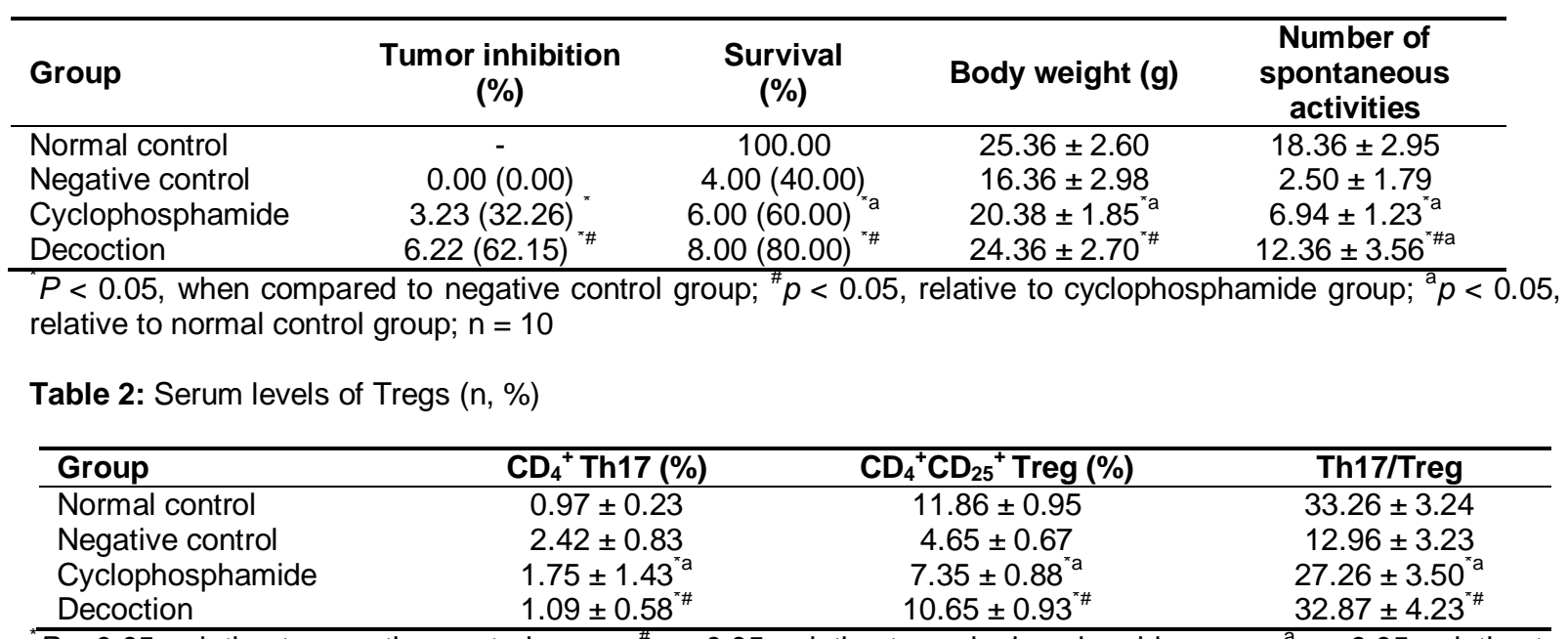

P<0.05, relative to negative control group; ${ }^{\#} p<0.05$, relative to cyclophosphamide group; ${ }^{a} p<0.05$, relative to normal control group; $n=10$ 


\section{Serum levels of P21 protein and VEGF}

Table 4 shows significantly lower serum levels of P21 protein and VEGF in decoction group than in negative control and cyclophosphamide groups. These parameters were markedly lower in cyclophosphamide group than in negative control group $(p<0.05)$. However, serum P21 protein and VEGF levels were comparable in the decoction and normal control groups $(p>0.05)$.

Table 4: P21 protein and VEGF levels in serum

\begin{tabular}{lcc}
\hline Group & $\begin{array}{c}\text { Serum P21 } \\
\text { protein } \\
(\mathbf{p g} / \mathbf{L})\end{array}$ & VEGF $(\boldsymbol{\mu} / \mathbf{L})$ \\
\hline Normal control & $25.36 \pm 2.87$ & $1.23 \pm 0.45$ \\
Negative control & $32.13 \pm 4.12$ & $3.38 \pm 0.47$ \\
Cyclophosphamide & $28.26 \pm$ & $1.78 \pm 0.40^{* a}$ \\
& $3.80^{* a}$ & \\
Decoction & $26.03^{* \#}$ & $1.28 \pm 0.73^{* \#}$ \\
\hline
\end{tabular}

$p<0.05$, relative to negative control group; ${ }^{\#} p<0.05$, relative to cyclophosphamide group; ${ }^{a} p<0.05$, relative to the normal control group; $n=10$

\section{Thymus and spleen indices}

Thymus and spleen indices were significantly elevated in the decoction group, when compared with the negative control and cyclophosphamide groups $(p<0.05)$, but were not significantly different from those of normal control group $(p>$ 0.05; Table 5).

Table 5: Thymus and spleen indices

\begin{tabular}{lcc}
\hline Group & $\begin{array}{c}\text { Thymus } \\
\text { index }\end{array}$ & $\begin{array}{c}\text { Spleen } \\
\text { index }\end{array}$ \\
\hline Normal control & $2.34 \pm 0.48$ & $8.61 \pm 0.75$ \\
Negative control & $1.62 \pm 0.23$ & $5.63 \pm 2.42$ \\
Cyclophosphamide & $1.73 \pm 0.48$ & $5.87 \pm 1.65$ \\
Decoction & $2.35 \pm 0.45^{\#}$ & $7.54 \pm 3.95^{\text {*\# }}$ \\
\hline
\end{tabular}

$P<0.05$, relative to negative control group: ${ }^{\#} p<0.05$, relative to cyclophosphamide group; $\mathrm{n}=10$

\section{DISCUSSION}

The pathogenesis of LC is quite complicated, and is characterized by spleen and stomach weaknesses, sputum qi, blood deficiencies, eating disorders, qi stagnation and blood stasis. Liver damage induced by different factors results in Zheng qi weakness and poisonous phlegm and ultimately lead to LC [6,7]. Radiotherapy and chemotherapy kill tumor cells and also cause some degree of damage to normal cells. Therapeutics used in TCM significantly improve liver function and reduce incidents of adverse reactions. Therefore, the combination of Chinese medicine and surgery after chemotherapy constitutes an effective treatment strategy for LC.
This strategy involves detoxification, clearing of heat, enhancement of blood circulation, and removal of blood stasis, amongst others [8].

In the present study, tumor inhibition, survival, body weight and the number of spontaneous activities were appreciably enhanced in the decoction, relative to the negative control and cyclophosphamide groups. These results suggest that Yugan Sanjie decoction may effectively mitigate the clinical symptoms of LC and inhibit proliferation of the tumor cells. It is possible that constituents of the decoction contributed synergistically to the observed effects. Isatidis radix, Astragalus, Bupleurum, and Paeonia albiflora Pall enhance spleen function; Salvia miltiorrhiza regulates pain, while tangerine promotes blood circulation and joint function [9].

Cellular immunity is an important defense mechanism against tumor cells, and $T$ lymphocytes are involved in the regulation of immune function. The $\mathrm{CD} 4^{+} \mathrm{T}$ lymphocytes are the dominant cells of cellular immune system, and they differentiate into lymphocyte subsets such as T-helper cell 17 (Th17) and Treg. In turn, Th17 stimulates neutral cells and macrophages to secrete the inflammatory cytokine IL-6, thereby aggravating the inflammatory response. It is known that Treg inhibits the inflammatory response via the secretion of IL-8 and other factors which help to maintain stability of the autoimmune system.

Studies have shown that the incidence of many tumors are closely linked to the imbalance between the levels of Th17 and Treg. Dynamic balance between Th17 and Treg is important for prevention of the inflammatory response and maintenance of immune system stability $[10,11]$. Tumor necrosis factor $\alpha$ (TNF- $\alpha$ ), a small protein molecule secreted by macrophages directly kills and inhibits tumor cells, and it is presently recognized as the most potent anti-tumor cytokine. Interleukin-2 (IL-2) participates in humoral immunity and exerts an important immune function via the stimulation and activation of $T$ cells. Studies have shown that TNF- $\alpha$ and IL-2 levels are significantly lower in peripheral blood of patients with LC than in normal patients [12].

In this study, serum level of $\mathrm{CD} 4^{+}$Th17 was markedly low in the decoction group, relative to the negative control and cyclophosphamide groups. However, serum level of $\mathrm{CD}_{4}{ }^{+} \mathrm{CD}_{25}{ }^{+}$Treg and Th17/Treg were appreciably elevated in decoction group, when compared to the negative control and cyclophosphamide groups. Serum 
levels of TNF- $\alpha$ and IL-2 were markedly higher in decoction group than in negative control and cyclophosphamide groups. These results suggest that decoction of Yugan Sanjie may effectively improve immune function in mice. It is possible that Yugan Sanjie decoction inhibited the tumor via the regulation of neutral cells and macrophages, leading to the release of antigenic and other soluble factors which stimulated proliferation of natural killer (NK) cells. It is also possible that the decoction stimulated NK cell killing activity, induced interferon (IFN) secretion and activated macrophages which in turn killed tumor cells [13].

Studies have shown that serum P21 protein promotes the proliferation and differentiation of tumor cells by regulating signals related to the cells, and it is highly expressed in LC cells. The most effective regulator of tumor angiogenesis is VEGF, and it promotes the growth of vascular endothelial cells, increases permeability, growth and metastasis of tumor cells. Therefore, the inhibition of serum P21 protein and VEGF expression is important for inhibiting tumor growth [14].

In this study, serum levels of P21 protein and VEGF were significantly lower in decoction group than in negative control and cyclophosphamide groups, and were significantly lower in cyclophosphamide group than in negative control group. However, there were no significant differences in serum levels of P21 protein and VEGF between decoction and normal control groups. These results appear to suggest that decoction of Yugan Sanjie may inhibit tumor cell proliferation and invasion through various mechanisms, and are in agreement with those previously reported [15].

The thymus and spleen are two important immune organs, and their indices reflect the level of cell immunity. These indices were significantly higher in the decoction group than in the negative control and cyclophosphamide groups, but were comparable with those of the normal control group. These results appear to suggest that Yugan Sanjie decoction may confer some level of protection on immune organs, and thus may inhibit tumor proliferation. These findings are consistent with those reported previously [16].

\section{CONCLUSION}

Decoction of Yugan Sanjie effectively alleviates the symptoms of LC and improves immune function of mice by regulating serum levels of $T$ lymphocytes. It inhibits tumor angiogenesis by suppressing the expressions of serum P21 protein and VEGF. These findings provide scientific evidence in support of the use of Yugan Sanjie decoction as a new treatment strategy for LC.

\section{DECLARATIONS}

\section{Acknowledgement}

This work was supported by Project of Science and Technology Development of Traditional Chinese Medicine of Shandong Province of China (no. 2013ZDZK-129) and the Science and Technology Project of Yantai of China (no. 2014WS039).

\section{Conflict of interest}

No conflict of interest is associated with this work.

\section{Contribution of authors}

We declare that this work was done by the author(s) named in this article and all liabilities pertaining to claims relating to the content of this article will be borne by the authors. All authors read and approved the manuscript for publication. Song Tan conceived and designed the study; Song Tan, Aihua Hou, Wei Liu, Jinguo Wang, Xiaoming Huang and Yuejun Mu collected and analysed the data, while Yuejun $\mathrm{Mu}$ wrote the manuscript.

\section{REFERENCES}

1. Falkson G, Macintyre JM, Moertel CG, Johnson LA, Scherman RC. Primary liver cancer. An eastern cooperative oncology group trial. Cancer 2015; 54(6): 970-977.

2. Liang $H Y, L U$ ZM. Current status and confusion in comprehensive interventional therapy for hepatocellular carcinoma. J Clin Hepatol 2016; 1: 44-48.

3. Zhan $Y$, Ling C. Overview of TCM syndrome research in primary liver cancer. J Tradit Chin Med 2017; 58(2): 166-169.

4. $X u$ J. Therapeutic effect of entecavir combined with Qiangganyugan decoction on chronic hepatitis B. Clin Med 2016; 36(5): 49-51.

5. World Health Organization. Principles of laboratory animal care. WHO Chron 1985; 39: 51-56.

6. Song $H X$, Qiao $F$, Shao $M$. Research advances in traditional Chinese medicine treatment for primary liver cancer. J Clin Hepatol 2016; 32(1): 163-164.

7. Han ZY, Han Z, Zhu J. Traditional Chinese Medicine treatment of primary liver cancer. J Changchun Univ Chin Med 2016; 32(2): 426-429. 
8. Liao YH, Lin CC, Lai HC, Chiang JH, Lin JG, Li TC. Adjunctive Traditional Chinese Medicine therapy improves survival of liver cancer patients. Liver Int 2016; 35(12): 2595-2602.

9. Wang $\mathrm{H}$. Clinical analysis of combined treatment of Traditional Chinese Medicine and Western Medicine for chronic hepatitis B. Guangming J Chin Med 2016; 31(8): 1149-1150.

10. Wang ZF, Ma J, Wang H, Zhang L, Li N, Zhao XJ, Zhang $Z M$, Zhou SX, Duan FL. T-lymphocyte infiltration and its relationship with arginase-1 in primary hepatocellular carcinoma (HCC). Henan J Prev Med 2017; 28(1): 1-3.

11. Chen JJ, Wan L, Liu JJ, Kan HP. Changes of Tlymphocyte subsets and its relationship with CTCs, TTV and $H B V-D N A$ in patients with primary hepatocellular carcinoma. Mod Dig Interv 2016; 21(2): 190-193.

12. Song XS, Li YS, Zhang GJ. The experimental study on the effect of Trillium tschonoskii Maxim on immune functions of hepatoma mice. Med Recapitulate 2015; (19): 3597-3599.

13. Sun $L X, W u J$, Jiang JP. Qiangshen Yugan decoction combined with entecavir treatment for chronic hepatitis B 40 cases. Chin J Exp Trad Med Formulae 2013; 19(22): 287-290.

14. Sun $Y$, Zhang $A Q$, Gao FY. Immune effect of Shaoyao Ruangan recipe on hepatocarcinoma in tumor-bearing H22 mice and its effect on VEGF and PCNA expressions. J Emerg Trad Chin Med 2015; 4: 590-592.

15. Zou $X M$, Si $T$, Ning $X J$, Wang SH, Feng $X B$, Shi $Y$. Clinical Study on Baogan Lishui Decoction in Treating Ascites in Patients with Advanced Primary Liver Cancer. Hebei J Trad Chin Med 2018; 40(2): 210-213.

16. Li H, Wang $H$, Peng $C$, Zheng $X$, Liu J, Weng ZH, Yang $D L$. Predictors for efficacy of combination therapy with a nucleos(t)ide analogue and interferon for chronic hepatitis B. J Huazhong Univ Sci Technol Med Sci 2017; 37(4): 547-555. 